\title{
Shakeppeate's
}

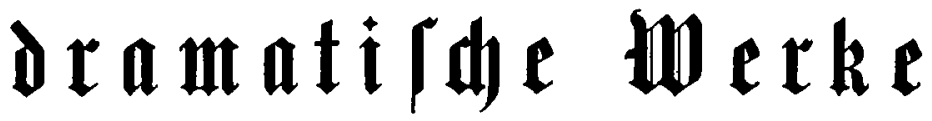

nact) ber Ueberiegutug

xilt

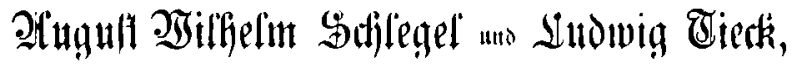

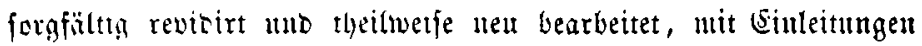
un Moten weriehen, unter Æeraction

jont

\section{f.) $\mathfrak{U} \mathfrak{I} \mathfrak{i} \mathfrak{i}$}

herausgegeken Durds bie

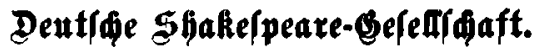

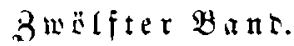

Berlin,

Berlag von (Siecrg ßeinter.

1871. 
